\title{
Effects of Magnetic Field and Internal Heat Generation on Triple Diffusive Convection in an Oldroyd-B Liquid
}

\author{
Gayathri Melathil, Subbarama Pranesh, and Sameena Tarannum
}

\begin{abstract}
The effects of magnetic field and internal heat generation on three component convection in an Oldroyd-B liquid is examined using Galerkin method. A linearized stability analysis is done to examine the system and the Rayleigh number is derived for oscillatory convection. The effect of viscoelastic parameters, internal Rayleigh number, solute Rayleigh numbers, Chandrasekhar number, Prandtl number and diffusion parameters have been inspected and depicted graphically for free-free, rigid-rigid and rigid-free velocity boundary combinations with isothermal and isoconcentration boundaries. Stress relaxation parameter, internal Rayleigh number, and solute Rayleigh numbers are observed to accelerate the onset of convection. Strain retardation parameter, Prandtl number, Chandrasekhar number and ratio of diffusivity of solutes and heat diffusivity are observed to decelerate the onset of convection.
\end{abstract}

Index Terms: Internal Heat Source, Magnetic Field, Oldroyd B Fluid, Triple Diffusive Convection, Viscoelastic Fluid.

\section{INTRODUCTION}

In several fields such as petroleum industries, chemical engineering and Geothermal regions, it is pragmatic that it is not just enough to study the effect of single or two-component convections but to also study the multi-component convection. For instance, in geothermal regions, the lower part of the earth's crust, predominantly the aquifers, is considered to be a fluid consisting of multi-components. Triple-component convection is the study of multi-component convection which involves three components with different individualistic properties. Griffiths [1] initiated the theoretical study of triple diffusive convection which was followed by Pearlstein et al. [2] who conducted a comprehensive study on the same.

Manuscript revised June 15, 2019 and published on July 10, 2019 Gayathri M, Department of Mathematics, CHRIST(deemed to be University), Bengaluru, India.

Subbarama Pranesh, Department of Mathematics, CHRIST(deemed to be University), Bengaluru, India.

Sameena Tarannum, Department Professional Studies, CHRIST(deemed to be University), Bengaluru, India.
Poulikakos [3] and Rudraiah and Vortmeyer [4] were the first to study the influence of triple diffusive convection in porous medium and Rionero [5] conducted a thorough theoretical investigation on the same. Lopez et al. [6] studied the triply diffusive fluid confined between rigid parallel boundaries. Other studies on triple diffusive convection includes Shivakumara and Naveen [7] and Sameena and Pranesh [8 - 10].

Viscoelastic liquids are those that possess the consolidation of liquid and solid charactersitics. When a viscoelastic liquid is subjected to stress, it primarily responds elastically to strain like a solid but when large amount of stress is introduced, it flows like a fluid. Viscoelastic liquids are composed of macromolecules immersed in Newtonian liquid. Most bio fluids like mucus, saliva, sputum and synovial fluids are viscoelastics. Further, oil, liquid polymers, glycerines, toothpaste, clay, etc. are viscoelastic. Due to their unique properties, they have a wide range of applications in fields like petroleum industry, bioengineering, geothermal energy modelling, solar receivers and so on.

There are several models to study viscoelastic liquids like Maxwell model, Jeffrey model, White-Wetzner model, Oldroyd-B model, and few more. However, Oldroyd-B liquid presents one of the simplest constitutive models capable of describing the viscoelastic behavior of dilute polymeric solutions under general flow conditions and is equivalent to a fluid filled with elastic bead and spring dumbbells. This model can be regarded as an extension of the Upper Convected Maxwell model and gets reduced to it when the solvent viscosity is zero. Owing to the unique properties several researchers have studied viscoelastic liquids including Mahantesh and Sidram[11], Sumathi and Aiswarya[12], Srivastava and Singh[13], Malashetty et al.[14] and Banyal[15].

The influence of magnetic field on the onset of convection has been another fascinating concepts since several years due to its significance in astrophysics, geophysics, nuclear engineering, crystal growth and so on. Magnetic field is a tool to control the flow such as in the case of bulk semiconductor crystal growth. A few studies on convection with magnetic field include Thakur and Rana[16], Pardeep et al.[17], Kashif et al.[18], and Siddheshwar and Pranesh[19].

Natural convections are driven by internal heating like in atmospheres and mantle earth and it can be observed that the heat generated is not uniform. For instance, in atmosphere, the sunbeams are more absorbed in the uppermost layers. Internal heating can also be induced in 
man-made objects like induction heaters and microwave ovens and it can be similarly observed that the heat generated is not uniform. For instance, when electrical current is passed, heat is more generated in the outer layers of the material heated. Though internal heating plays a vital role in convection, it is mostly neglected. Bhattacharyya and Jena [20], Tasaka and Takeda [21], Bhadauria [21] and recently Kanchana [22] have studied internal heat generation in convection.

Having done extensive literature review; with the wide appications and the need for the study, the authors were motivated to investigate the effect of magnetic field and internal heat generation on triple diffusive convection in an Oldroyd-B liquid under different boundary conditions.

\section{MATHEMATICAL FORMULATION}

A layer of Oldroyd B liquid is confined between two horizontal plates of infinte length separated by a distance d. Let $\Delta \mathrm{T}, \Delta \mathrm{S}_{1}$ and $\Delta \mathrm{S}_{2}$ be the differences in temperature and solute concentrations, respectively of the liquid between the lower and upper plates. The physical configuration of the problem is as shown in figure 1 with a uniform magnetic field $\mathrm{H}_{0}$ acting along the $\mathrm{z}$ axis

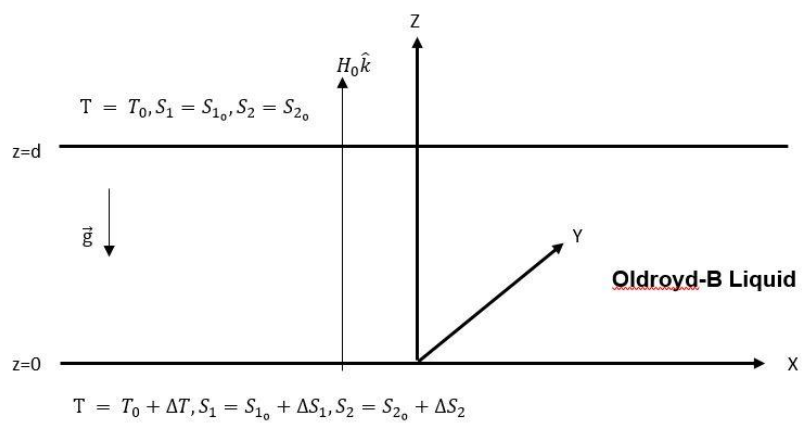

Figure 1: Physical Configuration

The governing equations for the given problem are:

$$
\begin{aligned}
& \nabla \cdot \vec{q}=0 \\
& \rho_{0}\left[\frac{\partial \vec{q}}{\partial t}+(\vec{q} \cdot \nabla) \vec{q}\right]=-\nabla P+\rho \vec{g}+\nabla \cdot \tau^{\prime}+\mu_{m}(\vec{H} \cdot \nabla) \overrightarrow{\mathrm{H}}, \# \\
& {\left[1+\lambda_{1} \frac{\partial}{\partial t}\right] \tau^{\prime}=\mu\left[1+\lambda_{2} \frac{\partial}{\partial t}\right]\left(\nabla \vec{q}+\nabla \vec{q}^{t r}\right), \#(3)} \\
& \frac{\partial T}{\partial t}+(\vec{q} \cdot \nabla) T=\chi_{t} \nabla^{2} T+Q\left(T-T_{0}\right), \#(4) \\
& \frac{\partial S_{1}}{\partial t}+(\vec{q} \cdot \nabla) S_{1}=\chi_{S_{1}} \nabla^{2} S_{1} \\
& \frac{\partial S_{2}}{\partial t}+(\vec{q} \cdot \nabla) S_{2}=\chi_{S_{2}} \nabla^{2} S_{2}, \#(6) \\
& \rho=\rho_{0}\left[1-\alpha_{t}\left(T-T_{0}\right)+\alpha_{S_{1}}\left(S_{1}-S_{1_{0}}\right)+\alpha_{S_{2}}\left(S_{2}-S_{2_{0}}\right)\right] \text {, } \\
& \frac{\partial \vec{H}}{\partial t}+(\vec{q} \cdot \nabla) \vec{H}=(\vec{H} \cdot \nabla) \vec{q}+\gamma_{m} \nabla^{2} \vec{H}, \#(8) \\
& \nabla \cdot \vec{H}=0 \text {, \#(9) }
\end{aligned}
$$

where, $\vec{q}$ is the velocity, $\mathrm{t}$ is the time, $\mathrm{P}$ is the hydromagnetic pressure, $\rho_{0}$ is the constant density, $\rho$ is the density, $\vec{g}$ is the gravitational force, $\vec{H}$ is the magnetic field, $\tau^{\prime}$ is the stress tensor, $\lambda_{1}$ is the stress relaxation time, $\lambda_{2}$ is the strain retardation time, $\mathrm{Q}$ is the internal heat source, $\mu$ is the viscosity, $\gamma_{m}=\frac{1}{\mu_{m} \sigma}, \mu_{m}$ is the magnetic permeability, $\sigma$ is the electrical conductivity, $\mathrm{T}$ is the temperature, $\mathrm{T}_{0}$ is the reference temperature, $S_{1}$ is the solute $1, S_{1_{0}}$ is the solute1 reference, $S_{2}$ is the solute2, $S_{2_{0}}$ is the solute 2 reference, $\chi_{t}$ is the thermal diffusivity, $\chi_{S_{1}}$ is the solute1 diffusivity, $\chi_{S_{2}}$ is the solute2 diffusivity, $\alpha_{t}$ is the coefficient of thermal expansion to determine how fast the density decreases with temperature, $\alpha_{S_{1}}$ is the coefficient of solute 1 expansion, $\alpha_{S_{2}}$ is the coefficient of solute 2 expansion.

Operating divergence on equation (3), and using (1) and (2) we get,

$$
\begin{gathered}
{\left[1+\lambda_{1} \frac{\partial}{\partial t}\right]\left[\rho_{0}\left[\frac{\partial \vec{q}}{\partial t}+(\vec{q} \cdot \nabla) \vec{q}\right]+\nabla P-\rho g-\mu_{m}(\vec{H} \cdot \nabla) \overrightarrow{\mathrm{H}}\right]=} \\
\mu\left[1+\lambda_{2} \frac{\partial}{\partial t}\right]\left(\nabla^{2} \vec{q}\right), \#(10)
\end{gathered}
$$

\section{BASIC STATE}

The basic state of the liquid being considered as motionless and is characterized by:

$$
\begin{gathered}
\vec{q}_{b}=(0,0,0), P=P_{b}(z), \rho=\rho_{b}(z), T=T_{b}(z), \\
, S_{1}=S_{1_{b}}(z), S_{2}=S_{2_{b}}(z), \overrightarrow{\mathrm{H}}=H_{0} \hat{k}, \#(11)
\end{gathered}
$$

Here subscript ' $b$ ' denotes the basic state of the liquid.

In the motionless state, equations (1) to (9) using equation (11) becomes

$$
\left.\begin{array}{c}
\frac{d P_{b}}{d z}+\rho_{b} g \hat{k}-\mu_{m} H_{0} \frac{d H_{0}}{d z}=0, \\
\chi_{t} \frac{d^{2} T_{b}}{d z^{2}}+Q\left(T_{b}-T_{0}\right)=0, \\
\frac{d^{2} S_{1_{b}}}{d z^{2}}=0, \\
\frac{d^{2} S_{2_{b}}}{d z^{2}}=0, \\
\rho_{b}=\rho_{0}\left[1-\alpha_{t}\left(T_{b}-T_{0}\right)+\alpha_{S_{1}}\left(S_{1_{b}}-S_{1_{0}}\right)+\alpha_{S_{2}}\left(S_{2_{b}}-S_{2_{0}}\right)\right], \\
\frac{d^{2} H_{b}}{d z^{2}}=0, \\
\nabla \cdot \overrightarrow{H_{b}}=0,
\end{array}\right)
$$

Solving second equation on (12) using boundary conditions

$$
\begin{aligned}
& T_{b}=T_{0}+\Delta \mathrm{T} \text { at } \mathrm{z}=0, T_{b}=T_{0} \text { at } \mathrm{z}=\mathrm{d} \\
& \text { we get, } \\
& \qquad T_{b}=T_{0}+\Delta T \frac{\sin \left(\sqrt{\frac{Q}{\kappa_{T}}}\left(1-\frac{z}{d}\right)\right)}{\sin \left(\sqrt{\frac{Q}{\kappa_{T}}}\right)} \#(13)
\end{aligned}
$$

IV. LINEAR STABILITY ANALYSIS

The following infinitesimal perturbation is introduced to the motionless basic state to examine the stability: 


$$
\left.\begin{array}{c}
\vec{q}=q_{b}+\vec{q}^{\prime}, P=P_{b}+P^{\prime}, \rho=\rho_{b}+\rho^{\prime}, T=T_{b}+T^{\prime} \\
S_{1}=S_{1_{b}}+S_{1}{ }^{\prime}, S_{2}=S_{2_{b}}+S_{2}{ }^{\prime}, \overrightarrow{\mathrm{H}}=H_{b}+\vec{H}^{\prime}
\end{array}\right\} \#
$$

where the prime quantities represent the perturbed quantity. Substituting equation (14) into equations (1)-(9) and using the basic state equations (12), we get linearised equations in the form:

$$
\begin{gathered}
\nabla \cdot \overrightarrow{q^{\prime}}=0, \#(15) \\
{\left[1+\lambda_{1} \frac{\partial}{\partial t}\right]\left[\rho_{0} \frac{\partial \overrightarrow{q^{\prime}}}{\partial t}+\nabla P^{\prime}+\rho^{\prime} g \hat{k}-\mu_{m}\left(\overrightarrow{H^{\prime}} \cdot \nabla\right) \overrightarrow{\mathrm{H}^{\prime}}\right.} \\
-\mu_{m}\left(H_{b}{ }^{\prime} \cdot \nabla\right) \overrightarrow{\mathrm{H}}^{\prime}-\mu_{m}\left(\overrightarrow{H^{\prime}} \cdot \nabla\right) H_{b} \\
=\mu\left[1+\lambda_{2} \frac{\partial}{\partial t}\right]\left(\nabla^{2} \overrightarrow{q^{\prime}}\right), \#(16) \\
\frac{\partial T^{\prime}}{\partial t}=\chi_{t} \nabla^{2} T^{\prime}+Q T^{\prime}+f(z) w^{\prime}, \#(17)
\end{gathered}
$$

where $f(z)=\frac{d T_{b}}{d z}$

$$
\begin{gathered}
\frac{\partial S_{1}{ }^{\prime}}{\partial t}=\chi_{S_{1}} \nabla^{2} S_{1}^{\prime}+\frac{\Delta S_{1}}{d} w^{\prime} \#(18) \\
\frac{\partial S_{2}{ }^{\prime}}{\partial t}=\chi_{S_{2}} \nabla^{2} S_{2}^{\prime}+\frac{\Delta S_{2}}{d} w^{\prime} \#(19) \\
\frac{\partial \vec{H}^{\prime}}{\partial t}=H_{0} \frac{\partial w^{\prime}}{\partial z} \hat{k}+\gamma_{m} \nabla^{2} \vec{H} \#(20) \\
\nabla \cdot \frac{\partial z}{H^{\prime}}=0, \#(21) \\
\rho^{\prime}=-\rho_{0}\left(\alpha_{t} T^{\prime}-\alpha_{S_{1}} S_{1}{ }^{\prime}-\alpha_{S_{2}} S_{2}{ }^{\prime}\right) \#(
\end{gathered}
$$

Substituting (22) in (16), we get

$$
\begin{gathered}
{\left[1+\lambda_{1} \frac{\partial}{\partial t}\right]\left[\rho_{0} \frac{\partial \overrightarrow{q^{\prime}}}{\partial t}+\nabla P^{\prime}-\rho^{\prime} g\left(\alpha_{t} T^{\prime}-\alpha_{S_{1}} S_{1}{ }^{\prime}-\alpha_{S_{2}} S_{2}{ }^{\prime}\right) \hat{k}-\right.} \\
-\mu_{m} H_{0} \frac{\partial \vec{H}^{\prime}}{\partial z}=\mu\left[1+\lambda_{2} \frac{\partial}{\partial t}\right]\left(\nabla^{2} \overrightarrow{q^{\prime}}\right), \#(23)
\end{gathered}
$$

Non-Dimensionalising equations (17),(18),(19),(20) and (23) using the following definitions,

$$
\left.\begin{array}{l}
\left(x^{*}, y^{*}, z^{*}\right)=\frac{1}{d}(x, y, z), \nabla^{*}=d \nabla, q^{*}=\frac{q^{\prime}}{\frac{\chi_{t}}{d}}, t^{*}=\frac{t^{\prime}}{\frac{d^{2}}{\chi_{t}}} \\
p^{*}=\frac{d^{2}}{\mu \chi_{t}} p^{\prime}, H^{*}=\frac{H^{\prime}}{H_{0}} T^{*}=\frac{T^{\prime}}{\Delta T}, S_{1}^{*}=\frac{S_{1}{ }^{\prime}}{\Delta S_{1}}, S_{2}^{*}=\frac{S_{2}{ }^{\prime}}{\Delta S_{2}}
\end{array}\right\}
$$

We obtain the following dimensionless equations (after dropping the asterisks)

$$
\begin{gathered}
\frac{\partial T}{\partial t}=\chi_{t} \nabla^{2} T+R_{i} T+f(z) w, \#(25) \\
\frac{\partial S_{1}}{\partial t}=\tau_{1} \nabla^{2} S_{1}+\frac{\Delta S_{1}}{d} w, \#(26) \\
\frac{\partial S_{2}}{\partial t}=\tau_{2} \nabla^{2} S_{2}+\frac{\Delta S_{2}}{d} w, \#(27) \\
\frac{\partial \vec{H}}{\partial t}=\frac{\partial w}{\partial z}+\frac{P r}{P m} \nabla^{2} \vec{H} \#(28) \\
{\left[1+\Lambda_{1} \frac{\partial}{\partial t}\right]\left[\frac{1}{\operatorname{Pr}} \frac{\partial \vec{q}}{\partial t}+\nabla P-\operatorname{RaT} \hat{k}+R_{S_{1}} S_{1} \hat{k}+R_{S_{2}} S_{2} \hat{k}\right.} \\
\left.-Q \frac{\operatorname{Pr}}{P m} \frac{\partial \vec{H}}{\partial z}\right]=\left[1+\Lambda_{2} \frac{\partial}{\partial t}\right]\left(\nabla^{2} \vec{q}\right), \#(29)
\end{gathered}
$$

where,

$\Lambda_{1}=\frac{\chi_{t} \lambda_{1}}{d^{2}} \quad$ (stress relaxation parameter or Deborah number)

$$
\Lambda_{2}=\frac{\chi_{t} \lambda_{2}}{d^{2}} \text { (strain retardation parameter) }
$$

$\operatorname{Pr}=\frac{\mu}{\rho_{0} \chi_{t}}$ (Prandtl number)

$P m=\frac{\mu}{\gamma_{m}}$ (magnetic Prandtl number)

$Q=\frac{\mu_{m} \sigma d^{2} H_{0}^{2}}{\mu}$ (Chandrasekhar number)

$R a=\frac{\rho_{0} \alpha_{t} g \Delta T d^{3}}{\mu \chi_{t}}$ (Rayleigh number)

$R i=\sqrt{\frac{Q}{\kappa_{T}}}$ (internal Rayleigh number)

$R_{S_{1}}=\frac{\rho_{0} \alpha_{S_{1}} g \Delta T d^{3}}{\mu \chi_{t}}$ (solute1 Rayleigh number)

$R_{S_{2}}=\frac{\rho_{0} \alpha_{S_{2}} g \Delta T d^{3}}{\mu \chi_{t}}$ (solute2 Rayleigh number)

$\tau_{1}=\frac{\chi_{S_{1}}}{\chi_{t}} \quad$ (ratio of diffusivity of solute 1 and heat diffusivity)

$\tau_{2}=\frac{\chi S_{2}}{\chi t} \quad$ (ratio of diffusivity of solute 2 and heat diffusivity)

Operating curl twice in equation (29) to eliminate the pressure term, we get (taking only the $\mathrm{k}$ components)

$$
\begin{gathered}
{\left[1+\Lambda_{1} \frac{\partial}{\partial t}\right]\left[\frac{1}{P r} \frac{\partial \nabla^{2} \vec{q}}{\partial t}-R a \nabla_{1}^{2} T+R_{S_{1}} \nabla_{1}^{2} S_{1}+R_{S_{2}} \nabla_{1}^{2} S_{2}\right.} \\
\left.-Q \frac{P r}{P m} \nabla^{2} \frac{\partial \vec{H}}{\partial z}\right]=-\left[1+\Lambda_{2} \frac{\partial}{\partial t}\right]\left(\nabla^{4} \mathrm{w}\right), \#(30)
\end{gathered}
$$

\section{NORMAL MODE ANALYSIS}

Let the periodic form of velocity, magnetic field, temperature, solute 1 and solute 2 be given as follows:

$$
\left[\begin{array}{c}
W \\
H \\
T \\
S_{1} \\
S_{2}
\end{array}\right]=\left[\begin{array}{c}
w(z) \\
H(z) \\
\theta(z) \\
\phi_{1}(z) \\
\phi_{2}(z)
\end{array}\right] e^{i(l x+m y)+\sigma t} \#(31)
$$

where 1 and $\mathrm{m}$ are horizontal wave numbers and $\sigma$ is the frequency. Substituting equation (31) in equations (25),(26),(27),(28) and (30), we obtain the following

$$
\begin{gathered}
\sigma \theta(z)=\left(D^{2}-a^{2}\right) \theta(z)+\operatorname{Ri\theta }(z)+f(z) w(z), \#(32) \\
\sigma \phi_{1}(z)=\left(D^{2}-a^{2}\right) \phi_{1}(z)+w(z), \#(33) \\
\sigma \phi_{2}(z)=\left(D^{2}-a^{2}\right) \phi_{2}(z)+w(z), \#(34) \\
\sigma H(z)=D w(z)+\frac{P r}{P m}\left(D^{2}-a^{2}\right) H(z), \#(35) \\
{\left[1+\Lambda_{1} \sigma\right]\left[\frac{\sigma}{P r}\left(D^{2}-a^{2}\right) w(z)+R a a^{2} \theta(z)\right.} \\
\left.-R_{S_{1}} a^{2} \phi_{1}(z)-R_{S_{2}} a^{2} \phi_{2}(z)-Q \frac{P r}{P m}\left(D^{2}-a^{2}\right) D H(z)\right] \\
=\left[1+\Lambda_{2} \sigma\right]\left(D^{2}-a^{2}\right)^{2} w(z),
\end{gathered}
$$

where $D=\frac{d}{d z}, a^{2}=l^{2}+m^{2}$

We solve equations (32) to (36) using Galerkin method. For a single term Galerkin expansion, we take velocity, magnetic field, temperature and concentration as $w(z, t)=A(t) w_{1}(z), H(z, t)=B(t) H_{1}(z), \theta(z, t)=$ $C(t) \theta_{1}(z), \phi_{1}(z, t)=E(t) \phi_{11}(z), \phi_{2}(z, t)=$

$F(t) \phi_{21}(z)$ where $\mathrm{A}, \mathrm{B}, \mathrm{C}, \mathrm{E}, \mathrm{F}$ are constants and $w_{1}, \zeta_{1}, \theta, \phi_{11}, \phi_{21}$ are trial functions. Multiply equation (32) by $\theta$, (33) by $\phi_{1}$, (34) by $\phi_{2}$, (35) by w and (36) by $\mathrm{H}$ and integrate between 0 and 1 .

We then obtain the following expression for Rayleigh number, $\mathrm{Ra}$ 


$$
\begin{aligned}
R a= & \frac{\sigma M_{12}-M_{4}-R i M_{12}}{a^{2} M_{8}^{2}}\left[\frac{-\sigma}{P r} M_{2}+\right. \\
& \frac{R_{S_{1}} a^{2} M_{9}^{2}}{\sigma M_{13}-\tau_{1} M_{5}}+\frac{R_{S_{2}} a^{2} M_{10}^{2}}{\sigma M_{14}-\tau_{2} M_{6}}+ \\
& \left.Q \frac{P r}{P m} \frac{M_{7}}{\sigma M_{11}-\frac{P r}{P m} M_{3}}+\frac{\left[1+\Lambda_{2} \sigma\right]}{\left[1+\Lambda_{1} \sigma\right]} M_{1}\right]
\end{aligned}
$$

where

$$
\begin{aligned}
& M_{1}=\left\langle w_{1}\left(D^{2}-a^{2}\right)^{2} w_{1}\right\rangle, M_{2}=\left\langle w_{1}\left(D^{2}-a^{2}\right) w_{1}\right\rangle, M_{3} \\
& =\left\langle\zeta_{1}\left(D^{2}-a^{2}\right) \zeta_{1}\right\rangle \text {, } \\
& M_{4}=\left\langle\theta_{1}\left(D^{2}-a^{2}\right) \theta_{1}\right\rangle, M_{5}=\left\langle\phi_{11}\left(D^{2}-a^{2}\right) \phi_{11}\right\rangle, M_{6} \\
& =\left\langle\phi_{21}\left(D^{2}-a^{2}\right) \phi_{21}\right\rangle \text {, } \\
& M_{7}=\left\langle w_{1} D \zeta_{1}\right\rangle\left\langle\zeta_{1} D w_{1}\right\rangle, M_{8}=\left\langle w_{1} f(z) \theta_{1}\right\rangle, M_{9} \\
& =\left\langle w_{1} \phi_{11}\right\rangle, M_{10}=\left\langle w_{1} \phi_{21}\right\rangle, \\
& M_{11}=\left\langle\zeta_{1}^{2}\right\rangle, M_{12}=\left\langle\theta_{1}^{2}\right\rangle, M_{13}=\left\langle\phi_{11}^{2}\right\rangle, M_{14}=\left\langle\phi_{21}^{2}\right\rangle \text {. }
\end{aligned}
$$

When $\sigma=0, R a$ is independent of viscoelastic parameters and is therefore equivalent to the expression obtained for the case of viscous Newtonian fluid. Hence, as far as the stationary convection is concerned,there is no distinction between viscous fluid and viscoelastic fluid. Thus we are not considering stationary convection in this paper.

Putting $\sigma=\mathrm{i} \omega$ in equation (37), separating the real and imaginary parts, and equating the imaginary part to zero we get

$x_{1}\left(\omega^{2}\right)^{4}+x_{2}\left(\omega^{2}\right)^{3}+x_{3}\left(\omega^{2}\right)^{2}+x_{4} \omega^{2}+x_{5}$,

where

$x_{1}=\Lambda_{1} M_{11}^{2} M_{13}^{2} M_{14}^{2}\left(\Lambda_{2} M_{1} M_{12}+\Lambda_{1}\left(M_{4}+R i M_{12}\right) \frac{M_{2}}{P r}\right)$

$x_{2}=M_{11}^{2} M_{13}^{2} M_{14}^{2}\left[M_{1} M_{12}+\left(M_{4}+R i M_{12}\right)\left(\frac{M_{2}}{P r}-\right.\right.$

$\left.\left.M_{1}\left(\Lambda_{2}-\Lambda_{1}\right)\right)\right]+\left[\Lambda_{1} M_{11}^{2}\left(\tau_{2}^{2} M_{6}^{2} M_{13}^{2}+\tau_{1}^{2} M_{5}^{2} M_{14}^{2}\right)+\right.$

$\left.\Lambda_{1} M_{13}^{2} M_{14}^{2}\left(\frac{P r}{P m}\right)^{2} M_{3}^{2}\right]\left[\Lambda_{2} M_{1} M_{12}+\Lambda_{1} \frac{M_{2}}{P r}\left(M_{4}+\right.\right.$

$\left.\left.R i M_{12}\right)\right]-R_{S_{1}} a^{2} M_{9}^{2} \Lambda_{1}^{2} M_{11}^{2} M_{14}^{2}\left[\tau_{1} M_{5} M_{12}-\right.$

$\left.\left(M_{4}+R i M_{12}\right) M_{13}\right]-R_{S_{2}} a^{2} M_{10}^{2} \Lambda_{1}^{2} M_{11}^{2} M_{13}^{2}\left[\tau_{2} M_{6} M_{12}-\right.$

$\left.\left(M_{4}+R i M_{12}\right) M_{14}\right]-Q \frac{P r}{P m} \Lambda_{1}^{2} M_{7} M_{13}^{2} M_{14}^{2}\left[M_{3} M_{12} \frac{P r}{P m}-\right.$

$\left.\left(M_{4}+R i M_{12}\right) M_{11}\right]$

$x_{3}=$

$\left[M_{11}^{2}\left(\tau_{1}^{2} M_{5}^{2} M_{14}^{2}+\right.\right.$

$\left.\left.\tau_{2}^{2} M_{6}^{2} M_{13}^{2}\right)+M_{13}^{2} M_{14}^{2}\left(\frac{P r}{P m}\right)^{2} M_{3}^{2}\right]\left[M_{1} M_{12}+\left(M_{4}+\right.\right.$

$\left.\left.\operatorname{Ri} M_{12}\right)\left(\frac{M_{2}}{P r}-M_{1}\left(\Lambda_{2}-\Lambda_{1}\right)\right)\right]+\Lambda_{1}\left[M_{11}^{2} \tau_{1}^{2} M_{5}^{2} \tau_{2}^{2} M_{6}^{2}+\right.$

$\left.\left(\tau_{2}^{2} M_{6}^{2} M_{13}^{2}+\tau_{1}^{2} M_{5}^{2} M_{14}^{2}\right)\left(\frac{P r}{P m}\right)^{2} M_{3}^{2}\right]\left[\Lambda_{2} M_{1} M_{12}+\right.$

$\left.\Lambda_{1} \frac{M_{2}}{P r}\left(M_{4}+R i M_{12}\right)\right]-R_{S_{1}} a^{2} M_{9}^{2}\left[M_{11}^{2} M_{14}^{2}+\right.$

$\left.\Lambda_{1}^{2} M_{14}^{2}\left(\frac{P r}{P m}\right)^{2} M_{3}^{2}+\Lambda_{1}^{2} M_{11}^{2} \tau_{2}^{2} M_{6}^{2}\right]\left[\tau_{1} M_{5} M_{12}-\right.$

$\left.\left(M_{4}+R i M_{12}\right) M_{13}\right]-R_{S_{2}} a^{2} M_{10}^{2}\left[M_{11}^{2} M_{13}^{2}+\right.$

$\left.\Lambda_{1}^{2} M_{13}^{2}\left(\frac{P r}{P m}\right)^{2} M_{3}^{2}+\Lambda_{1}^{2} M_{11}^{2} \tau_{1}^{2} M_{5}^{2}\right]\left[\tau_{2} M_{6} M_{12}-\right.$

$\left.\left(M_{4}+R i M_{12}\right) M_{14}\right]-$

$$
\begin{aligned}
& Q \frac{P r}{P m} M_{7}\left[M_{13}^{2} M_{14}^{2}+\right. \\
& \left.\Lambda_{1}^{2}\left(\tau_{2}^{2} M_{6}^{2} M_{13}^{2}+\tau_{1}^{2} M_{5}^{2} M_{14}^{2}\right)\right]\left[M_{3} M_{12} \frac{P r}{P m}-\left(M_{4}+\right.\right. \\
& \left.\left.R i M_{12}\right) M_{11}\right] \\
& x_{4}=\left[M_{11}^{2} \tau_{1}^{2} M_{5}^{2} \tau_{2}^{2} M_{6}^{2}+\left(\frac{P r}{P m}\right)^{2} M_{3}^{2}\left(\tau_{1}^{2} M_{5}^{2} M_{14}^{2}+\right.\right. \\
& \left.\left.\tau_{2}^{2} M_{6}^{2} M_{13}^{2}\right)\right]\left[M_{1} M_{12}+\left(M_{4}+R i M_{12}\right)\left(\frac{M_{2}}{P r}-\right.\right. \\
& \left.\left.M_{1}\left(\Lambda_{2}-\Lambda_{1}\right)\right)\right]+\Lambda_{1} \tau_{1}^{2} M_{5}^{2} \tau_{2}^{2} M_{6}^{2}\left(\frac{P r}{P m}\right)^{2} M_{3}^{2}\left[\Lambda_{2} M_{1} M_{12}+\right. \\
& \left.\Lambda_{1} \frac{M_{2}}{P r}\left(M_{4}+R i M_{12}\right)\right]-R_{S_{1}} a^{2} M_{9}^{2}\left[M_{14}^{2}\left(\frac{P r}{P m}\right)^{2} M_{3}^{2}+\right. \\
& \left.\left(M_{11}^{2}+\Lambda_{1}^{2}\left(\frac{P r}{P m}\right)^{2} M_{3}^{2}\right) \tau_{2}^{2} M_{6}^{2}\right]\left[\tau_{1} M_{5} M_{12}-\left(M_{4}+\right.\right. \\
& \left.\left.R i M_{12}\right) M_{13}\right]-R_{S_{2}} a^{2} M_{10}^{2}\left[M_{13}^{2}\left(\frac{P r}{P m}\right)^{2} M_{3}^{2}+\right. \\
& \left.\left(M_{11}^{2}+\Lambda_{1}^{2}\left(\frac{P r}{P m}\right)^{2} M_{3}^{2}\right) \tau_{1}^{2} M_{5}^{2}\right]\left[\tau_{2} M_{6} M_{12}-\left(M_{4}+\right.\right. \\
& \left.\left.R i M_{12}\right) M_{14}\right]-Q \frac{P r}{P m} M_{7}\left[\tau_{2}^{2} M_{6}^{2} M_{13}^{2}+\tau_{1}^{2} M_{5}^{2} M_{14}^{2}+\right. \\
& \left.\Lambda_{1}^{2} \tau_{1}^{2} M_{5}^{2} \tau_{2}^{2} M_{6}^{2}\right]\left[M_{3} M_{12} \frac{P r}{P m}-\left(M_{4}+R i M_{12}\right) M_{11}\right] \\
& x_{5}=\tau_{1}^{2} M_{5}^{2} \tau_{2}^{2} M_{6}^{2}\left(\frac{P r}{P m}\right)^{2} M_{3}^{2}\left[M_{1} M_{12}+\left(M_{4}+\right.\right. \\
& \left.R i M_{12}\right)\left(\frac{M_{2}}{P r}-\right. \\
& \left.\left.M_{1}\left(\Lambda_{2}-\Lambda_{1}\right)\right)\right]-R_{S_{1}} a^{2} M_{9}^{2} \tau_{2}^{2} M_{6}^{2}\left(\frac{P r}{P m}\right)^{2} M_{3}^{2}\left[\tau_{1} M_{5} M_{12}-\right. \\
& \left.\left(M_{4}+R i M_{12}\right) M_{13}\right]- \\
& R_{S_{2}} a^{2} M_{10}^{2} \tau_{1}^{2} M_{5}^{2}\left(\frac{P r}{P m}\right)^{2} M_{3}^{2}\left[\tau_{2} M_{6} M_{12}-\left(M_{4}+\right.\right. \\
& \left.\left.R i M_{12}\right) M_{14}\right]-Q \frac{P r}{P m} M_{7} \tau_{1}^{2} M_{5}^{2} \tau_{2}^{2} M_{6}^{2}\left[M_{3} M_{12} \frac{P r}{P m}-\right. \\
& \left.\left(M_{4}+R i M_{12}\right) M_{11}\right]
\end{aligned}
$$

Now equation (37) with imaginary part equal to zero becomes,

$$
\begin{gathered}
R a=\frac{1}{a^{2} M_{8}^{2}}\left\{\frac{M_{1}\left(-M_{4}-R_{i} M_{12}\right)\left(1+\omega^{2} \Lambda_{1} \Lambda_{2}\right)}{1+\Lambda_{1}^{2} \omega^{2}}\right. \\
-\left(\omega^{2} M_{12}\right)\left(\frac{M_{2}}{P r}-\frac{M_{1}\left(\Lambda_{2}-\Lambda_{1}\right)}{1+\Lambda_{1}^{2} \omega^{2}}\right) \\
-Q \frac{P r}{P m} \frac{M_{7}\left(\frac{P r}{P m}\left(-M_{4}-R_{i} M_{12}\right) M_{3}-\left(\omega^{2} M_{12}\right) M_{11}\right)}{\omega^{2} M_{11}^{2}+\left(\frac{P r}{P m}\right)^{2} M_{3}^{2}} \\
-\frac{R_{S_{1}} a^{2}\left(M_{9}\right)^{2}\left(\left(-M_{4}-R_{i} M_{12}\right) \tau_{1} M_{5}-\left(\omega^{2} M_{12}\right) M_{13}\right)}{\omega^{2} M_{13}^{2}+\tau_{1}^{2} M_{5}^{2}} \\
\left.-\frac{R_{S_{2}} a^{2}\left(M_{10}\right)^{2}\left(\left(-M_{4}-R_{i} M_{12}\right) \tau_{2} M_{6}-\left(\omega^{2} M_{12}\right) M_{14}\right)}{\omega^{2} M_{14}^{2}+\tau_{2}^{2} M_{6}^{2}}\right\}
\end{gathered}
$$

The value of critical Rayleigh number depends on the boundaries. In this paper, we consider the following boundary combinations:

(i) free-free velocity, isothermal and isoconcentration boundary conditions:

$$
\mathrm{w}=\frac{\partial^{2} w}{\partial z^{2}}=\mathrm{T}=S_{1}=S_{2}=\mathrm{D} H=0 \text { at } \mathrm{z}=0,1
$$

(ii) rigid-free velocity, isothermal and isoconcentration boundary conditions:

$$
\mathrm{w}=\frac{\partial w}{\partial z}=\mathrm{T}=S_{1}=S_{2}=\mathrm{D} H=0 \text { at } \mathrm{z}=0,
$$


$\mathrm{w}=\frac{\partial^{2} w}{\partial z^{2}}=\mathrm{T}=S_{1}=S_{2}=\mathrm{D} H=0$ at $\mathrm{z}=1$

(iii) rigid-rigid velocity, isothermal and isoconcentration boundary conditions:

$$
\mathrm{w}=\frac{\partial w}{\partial z}=\mathrm{T}=S_{1}=S_{2}=\mathrm{D} H=0 \text { at } \mathrm{z}=0,1 .
$$

The trial functions satisfying the boundary conditions are presented in Table 1.

Table 1: Trial functions for different boundary conditions.

\begin{tabular}{|r|r|r|r|}
\hline $\begin{array}{l}\text { Boundary } \\
\text { conditions }\end{array}$ & Free-Free & Rigid-Free & \multicolumn{1}{l|}{ Rigid-Rigid } \\
\hline$w_{1}$ & $z^{4}-2 z^{3}+z$ & $z^{4}-2 z^{3}+z^{2}$ & $2 z^{4}-5 z^{3}+3 z^{2}$ \\
\hline$H_{1}$ & $z^{2}(3-2 z)$ & $z^{2}(3-2 z)$ & $z^{2}(3-2 z)$ \\
\hline$\theta_{1}$ & $\mathrm{z}(1-\mathrm{z})$ & $\mathrm{z}(1-\mathrm{z})$ & $\mathrm{z}(1-\mathrm{z})$ \\
\hline$\phi_{1}$ & $\mathrm{z}(1-\mathrm{z})$ & $\mathrm{z}(1-\mathrm{z})$ & $\mathrm{z}(1-\mathrm{z})$ \\
\hline$\phi_{2}$ & $\mathrm{z}(1-\mathrm{z})$ & $\mathrm{z}(1-\mathrm{z})$ & $\mathrm{z}(1-\mathrm{z})$ \\
\hline
\end{tabular}

\section{RESULTS AND DISCUSSION}

In this paper, Galerkin method has been employed to study the effects of magnetic field and internal heat generation on three component convection in an OldroydB liquid. A linearized stability analysis is done to examine the system and the Rayleigh number is derived for oscillatory convection. The critical Rayleigh number obtained for different values of $\Lambda_{1}, \Lambda_{2}, T a, R i, R_{s_{1}}, R_{s_{2}}, \tau_{1}, \tau_{2}, P r$ and $P m$ in free-free, rigid-rigid and rigid-free velocity boundary combinations with isothermal and isoconcentration boundaries are illustrated in figures (2) - (4) respectively.

From these figures the following results can be analysed:

1. Figures 2(a), 3(a), 4(a) shows the variation of critical Rayleigh number for different values of stress relaxation parameter $\left(\Lambda_{1}\right)$ and strain retardation parameter $\left(\Lambda_{2}\right)$. Comparing the curves (1) and (2), we observe that the increase in $\Lambda_{1}$ decreases the critical Rayleigh number. $\Lambda_{1}$ is an elastic parameter and it signifies the relaxation of stress while having its impact on the liquid. Therefore, it can be concluded that $\Lambda_{1}$ accelerates the onset of convection and destabilizes the system. Comparing the curves (1) and (3), we observe that the increase in $\Lambda_{2}$ increases the critical Rayleigh number. $\Lambda_{2}$ is also an elastic parameter and it signifies the relaxation in liquid in responding to the stress. Therefore, it can be concluded that $\Lambda_{2}$ decelerates the onset of convection and stabilizes the system.

2. Figures 2(b), 3(b), 4(b) shows the variation of critical Rayleigh number for different values of Chandrasekhar number (Q). Comparing the three curves, we observe that increase in $\mathrm{Q}$ increases the critical Rayleigh number. The magnetic field that is applied generates current and this will connect with the magnetic field and leads to Lorentz force. The Lorentz force is in the direction opposite to that of the direction of velocity and hence the magnetic field. Therefore, it can be concluded that Q decelerates the onset of convection and stabilizes the system.

3. Figures 2(c), 3(c), 4(c) shows the variation of critical Rayleigh number for different values of solute1 Rayleigh number $\left(R_{S_{1}}\right)$ and solute2 Rayleigh number $\left(R_{S_{2}}\right)$. Comparing the curves (1) and (2), we observe that the increase in $R_{S_{1}}$ increases the critical Rayleigh number and comparing the curves (1) and (3), we observe that the increase in $R_{S_{2}}$ also increases the critical Rayleigh number. Since we add solutes from below, the concentration of solutes settles at the bottom without disturbing the system. Therefore it can be concluded that both $R_{S_{1}}$ and $R_{S_{2}}$ decelerates the onset of convection and stabilizes the system.

4. Figures 2(d), 3(d), 4(d) shows the variation of critical Rayleigh number for different values of internal Rayleigh number (Ri). Comparing the three curves, we observe that increase in $\mathrm{Ri}$ decreases the critical Rayleigh number. Increase in $\mathrm{Ri}$ increases the heat supply into system thereby advancing the onset of convection. Therefore we conclude that $\mathrm{Ri}$ accelerates the onset of convection and destabilizes the system.

5. Figures 2(e), 3(e), 4(e) shows the variation of critical Rayleigh number for different values of ratio of diffusivity of solute 1 and heat diffusivity $\left(\tau_{1}\right)$ and ratio of diffusivity of solute 1 and heat diffusivity $\left(\tau_{2}\right)$. Comparing the curves (1) and (2), we observe that the increase in $\tau_{1}$ decreases the critical Rayleigh number and comparing the curves (1) and (3), we observe that the increase in $\tau_{2}$ also decreases the critical Rayleigh number. Therefore it can be concluded that both $\tau_{1}$ and $\tau_{2}$ accelerates the onset of convection and destabilizes the system.

6. Figures 2(f), 3(f), 4(f) shows the variation of critical Rayleigh number for different values of Prandl number (Pr). Comparing the three curves, we observe that increase in Pr increases the critical Rayleigh number. Therefore we conclude that Pr decelerates the onset of convection and stabilizes the system.

7. Figures $2(\mathrm{~g}), 3(\mathrm{~g}), 4(\mathrm{~g})$ shows the variation of critical Rayleigh number for different values of magnetic Prandl number (Pm). Comparing the three curves, we observe that increase in $\mathrm{Pm}$ decreases the critical Rayleigh number. Therefore we conclude that Pm accelerates the onset of convection and destabilizes the system.

Tables 2 and 3 shows the comparison of critical Rayleigh number of Newtonian liquid, Maxwell liquid, Oldroyd-B liquid and Revlin Erickson liquid for $R_{S_{1}}$ and $R_{S_{2}}$ for fixed values of $\tau_{1}=0.4, \tau_{2}=0.5, \operatorname{Pr}=5$ and $\mathrm{Pm}=10$ for $\mathrm{Q}=50$ and $\mathrm{Q}=100$, respectively, in free-free, rigid- 
rigid and rigid-free velocity boundary combinations with isothermal and isoconcentration boundaries. We can observe that $\left(\mathrm{Ra}_{\mathrm{c}}\right)_{\mathrm{N}}>\left(\mathrm{Ra}_{\mathrm{c}}\right)_{\mathrm{RE}}>\left(\mathrm{Ra}_{\mathrm{c}}\right)_{\mathrm{O}}>\left(\mathrm{Ra}_{\mathrm{c}}\right)_{\mathrm{M}}$. This gives us the result that the Newtonian liquid is the most stable followed by Revlin Erickson liquid followed by Oldroyd-B liquid and then Maxwell liquid.

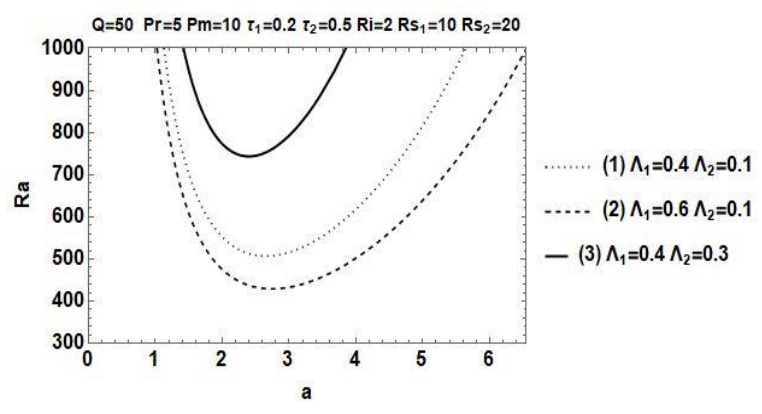

(a)

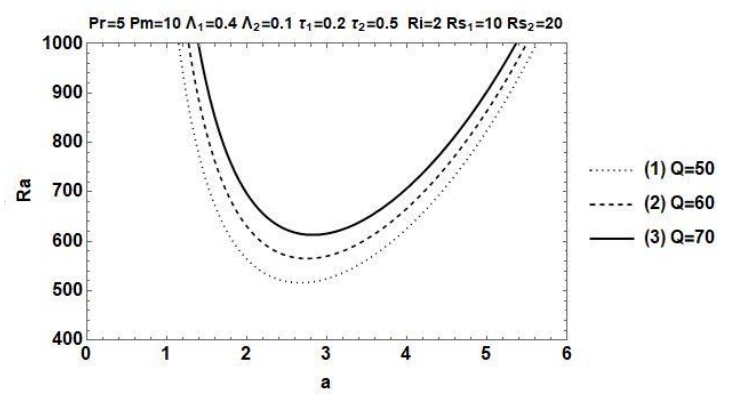

(b)

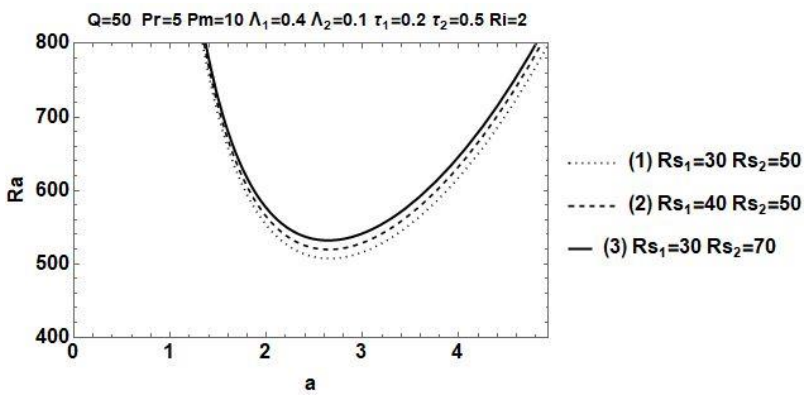

(c)

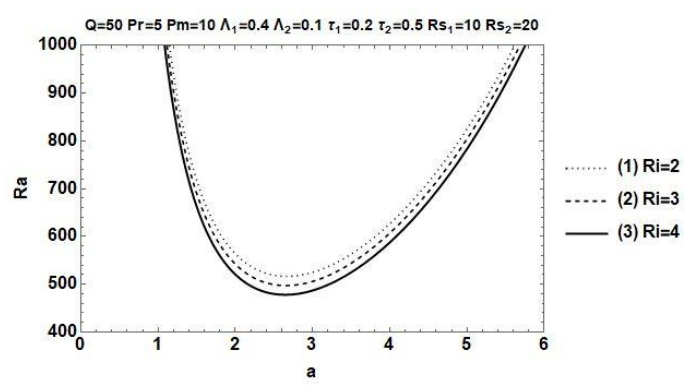

(d)

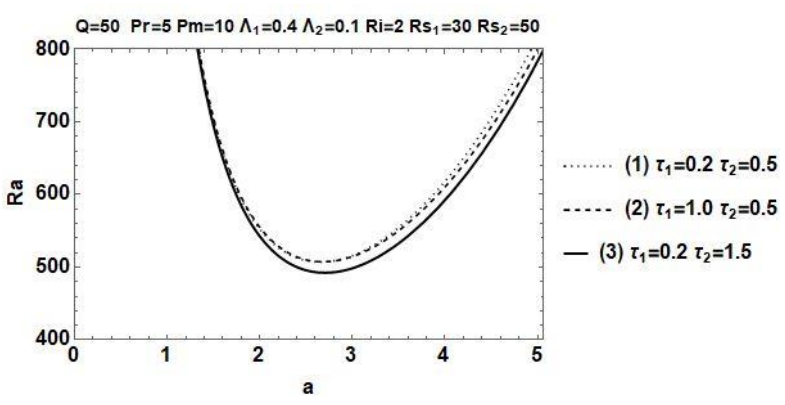

(e)

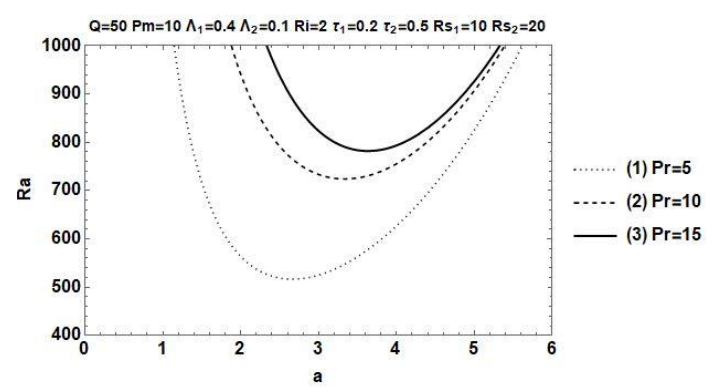

(f)

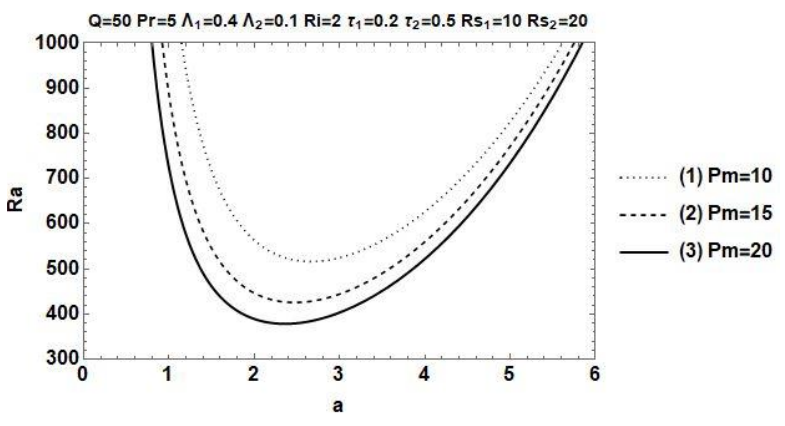

(g)

Figure 2: Neutral curves for free-free velocity boundary combination with isothermal and isoconcentration boundaries for oscillatory convection for different values of (a) $\Lambda_{1}, \Lambda_{2}$ (b) $Q$ (c) $R_{s_{1}}, R_{s_{2}}$ (d) $R i$ (e) $\tau_{1}, \tau_{2}$ (f) $\operatorname{Pr}$ (g) $\mathrm{Pm}$ 
International Journal of Research in Advent Technology, Vol.7, No.6, June 2019

E-ISSN: 2321-9637

Available online at www.ijrat.org

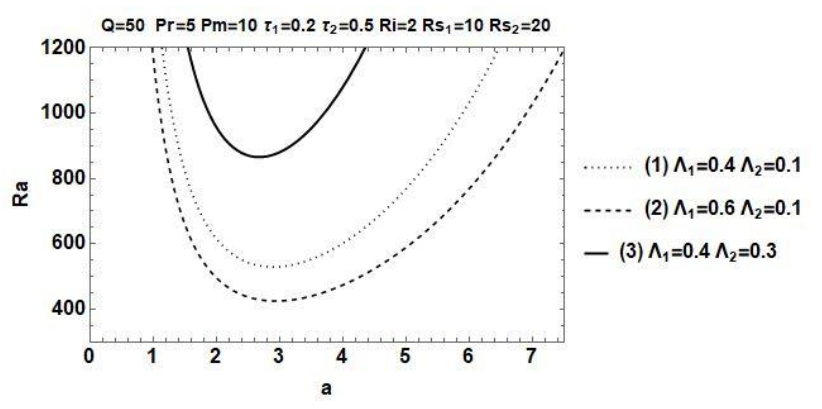

(a)

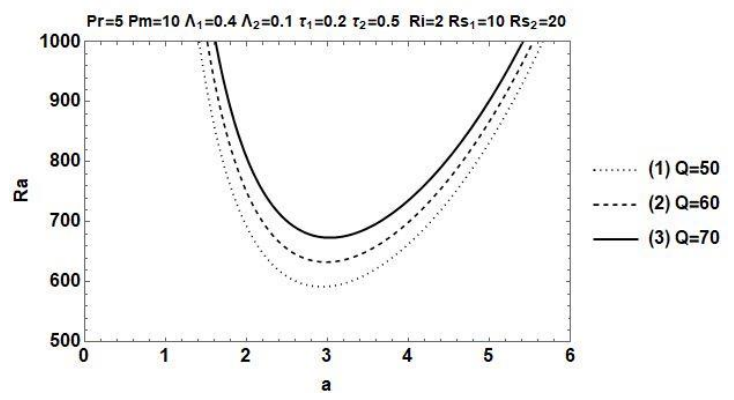

(b)

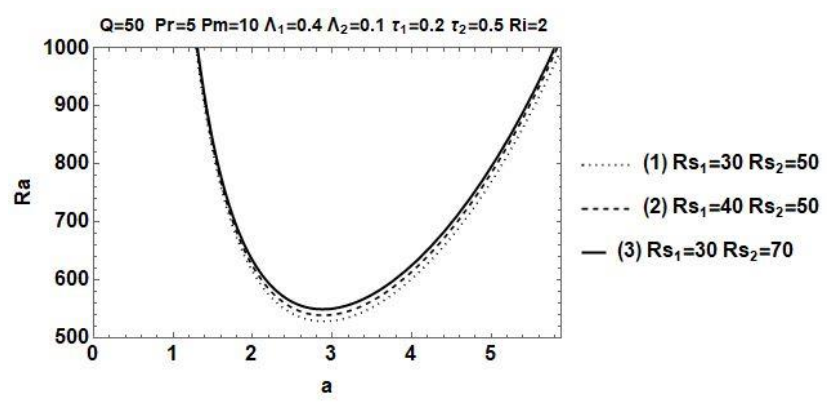

(c)

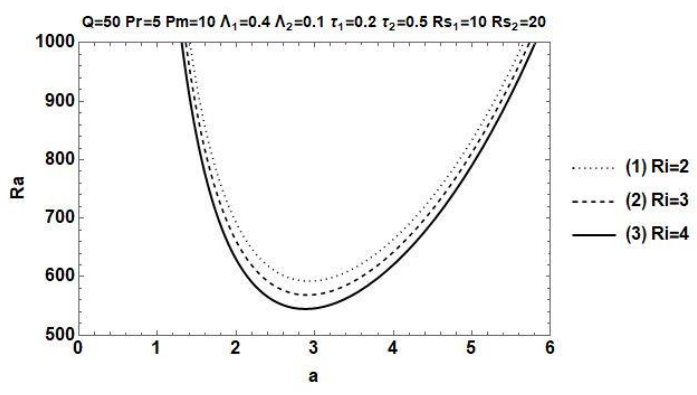

(d)

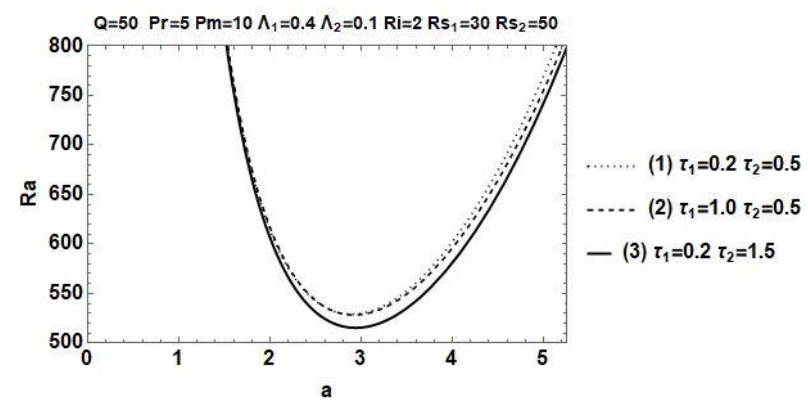

(e)

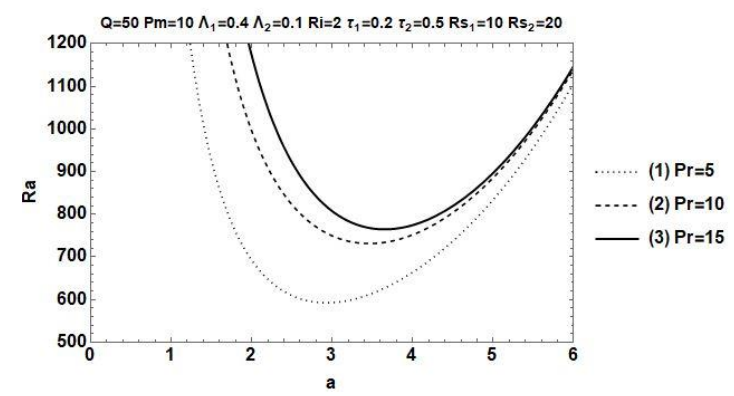

(f)

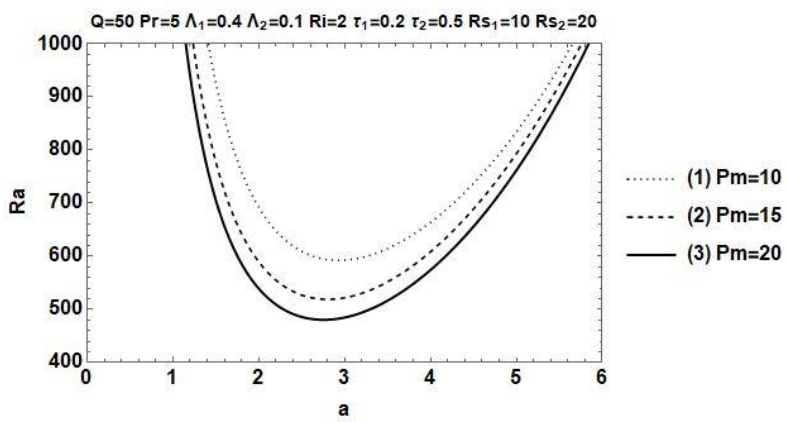

(g)

Figure 3: Neutral curves for rigid-free velocity boundary combination with isothermal and isoconcentration boundaries for oscillatory convection for different values of (a) $\Lambda_{1}, \Lambda_{2}$ (b) $Q$ (c) $R_{s_{1}}, R_{s_{2}}$ (d) $R i$ (e) $\tau_{1}, \tau_{2}$ (f) $\operatorname{Pr}$ (g) $P m$ 
International Journal of Research in Advent Technology, Vol.7, No.6, June 2019

E-ISSN: 2321-9637

Available online at www.ijrat.org

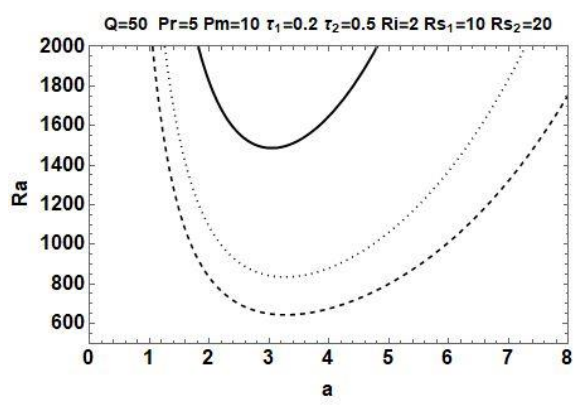

(a)

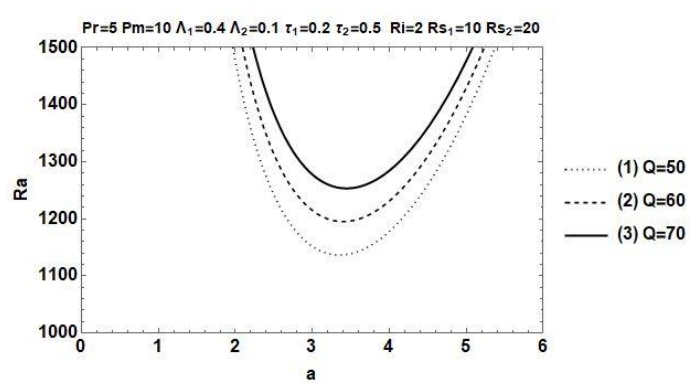

(b)

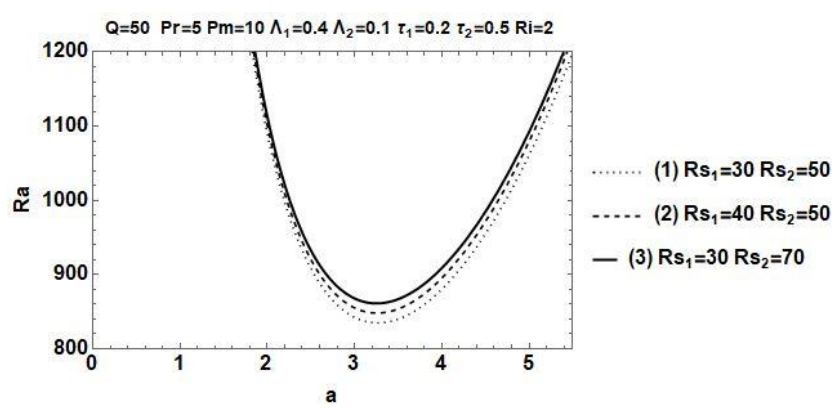

(c)

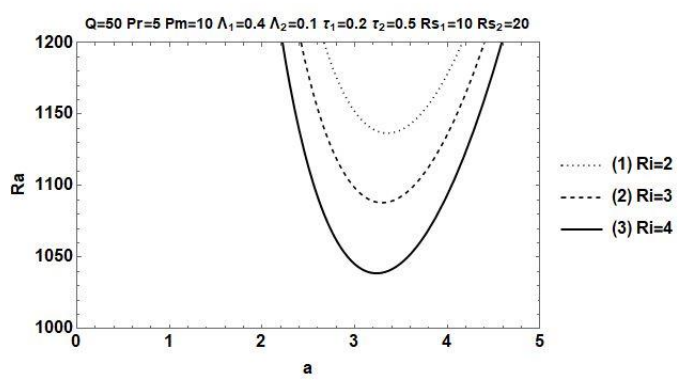

(d)

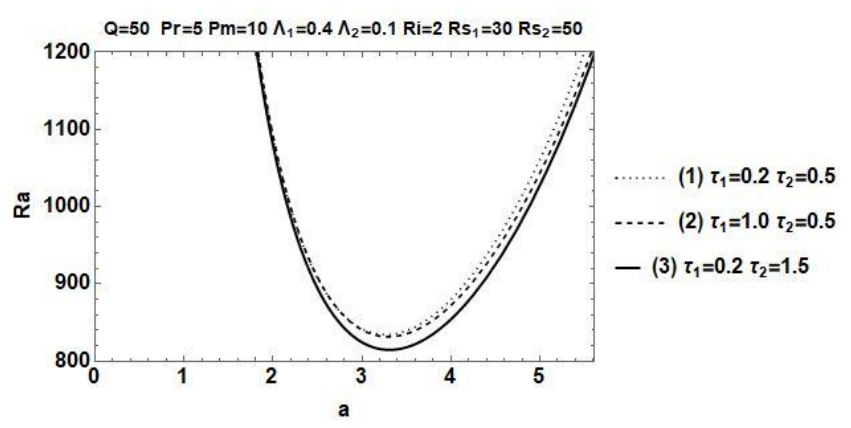

(e)
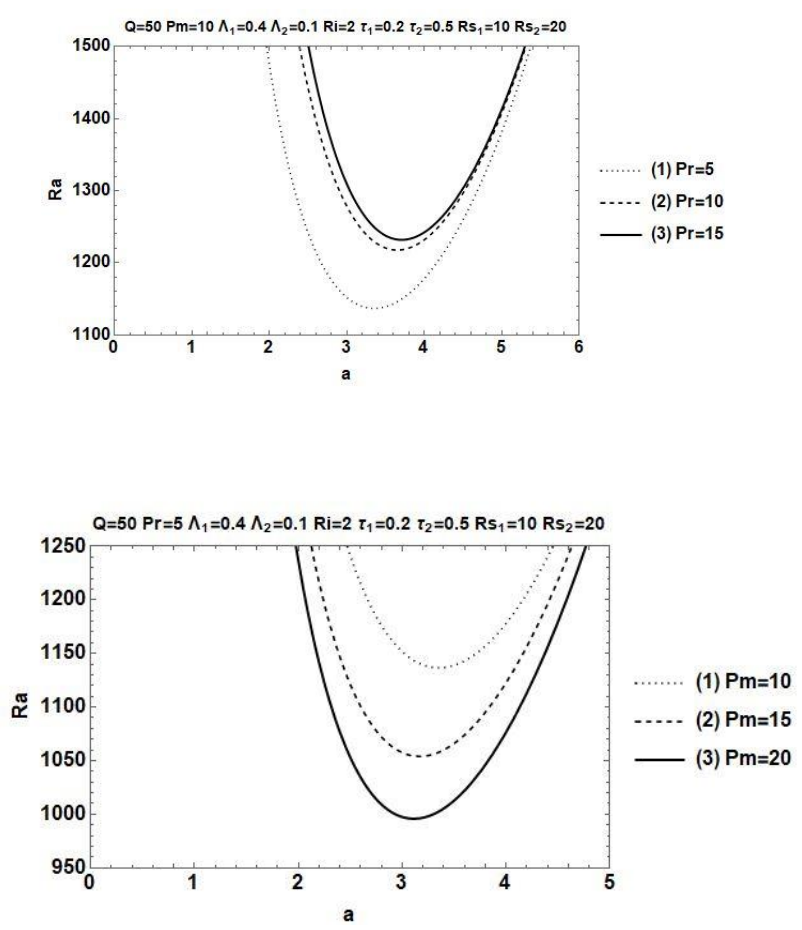

$(\mathrm{g})$

Figure 4: Neutral curves for rigid-rigid velocity boundary combination with isothermal and isoconcentration boundaries for oscillatory convection for different values of (a) $\Lambda_{1}, \Lambda_{2}$ (b) $Q$ (c) $R_{S_{1}}, R_{S_{2}}$ (d) $R i$ (e) $\tau_{1}, \tau_{2}$ (f) $\operatorname{Pr}$ (g) $\mathrm{Pm}$ 
Available online at www.ijrat.org

Table 2: Variation of critical Rayleigh number for Newtonian, Maxwell, Oldroyd-B and Revlin Erickson liquids with solute1 Rayleigh number $R_{S_{1}}$ and solute2 Rayleigh number $R_{S_{2}}$ for fixed values of $\tau_{1}=0.4, \tau_{2}=0.5, \mathrm{Q}=50 \operatorname{Pr}=5$ and $\mathrm{Pm}=10$

\begin{tabular}{|c|c|c|c|c|c|c|c|c|c|c|c|c|c|}
\hline \multirow[b]{2}{*}{$R_{S_{1}}$} & \multirow[b]{2}{*}{$R_{S_{2}}$} & \multicolumn{4}{|c|}{$\begin{array}{l}\text { Free Free Velocity, Isothermal, } \\
\text { Isoconcentration }\end{array}$} & \multicolumn{4}{|c|}{$\begin{array}{c}\text { Rigid Free Velocity, Isothermal, } \\
\text { Isoconcentration }\end{array}$} & \multicolumn{4}{|c|}{$\begin{array}{l}\text { Rigid Rigid Velocity, Isothermal, } \\
\text { Isoconcentration }\end{array}$} \\
\hline & & $\begin{array}{l}\left(\mathrm{Ra}_{\mathrm{c}}\right)_{\mathrm{N}} \\
\Lambda_{1}=0.4 \\
\Lambda_{2}=0.4\end{array}$ & $\begin{array}{l}\left(\mathrm{Ra}_{\mathrm{c}}\right)_{\mathrm{M}} \\
\Lambda_{1}=0.4 \\
\Lambda_{2}=0\end{array}$ & $\begin{array}{l}\left(\mathrm{Ra}_{\mathrm{c}}\right)_{\mathrm{O}} \\
\Lambda_{1}=0.4 \\
\Lambda_{2}=0.3\end{array}$ & $\begin{array}{l}\left(\mathrm{Ra}_{\mathrm{c}}\right)_{\mathrm{RE}} \\
\Lambda_{1}=0.001 \\
\Lambda_{2}=0.05\end{array}$ & $\begin{array}{l}\left(\mathrm{Ra}_{\mathrm{c}}\right)_{\mathrm{N}} \\
\Lambda_{1}=0.4 \\
\Lambda_{2}=0.4\end{array}$ & $\begin{array}{l}\left(\mathrm{Ra}_{\mathrm{c}}\right)_{\mathrm{M}} \\
\Lambda_{1}=0.4 \\
\Lambda_{2}=0\end{array}$ & $\begin{array}{l}\left(\mathrm{Ra}_{\mathrm{c}}\right)_{\mathrm{O}} \\
\Lambda_{1}=0.4 \\
\Lambda_{2}=0.3\end{array}$ & $\begin{array}{l}\left(\mathrm{Ra}_{\mathrm{c}}\right)_{\mathrm{RE}} \\
\Lambda_{1}=0.001 \\
\Lambda_{2}=0.05\end{array}$ & $\begin{array}{l}\left(\mathrm{Ra}_{\mathrm{c}}\right)_{\mathrm{N}} \\
\Lambda_{1}=0.4 \\
\Lambda_{2}=0.4\end{array}$ & $\begin{array}{l}\left(\mathrm{Ra}_{\mathrm{c}}\right)_{\mathrm{M}} \\
\Lambda_{1}=0.4 \\
\Lambda_{2}=0\end{array}$ & $\begin{array}{l}\left(\mathrm{Ra}_{\mathrm{c}}\right)_{\mathrm{O}} \\
\Lambda_{1}=0.4 \\
\Lambda_{2}=0.3\end{array}$ & $\begin{array}{l}\left(\mathrm{Ra}_{\mathrm{c}}\right)_{\mathrm{RE}} \\
\Lambda_{1}=0.001 \\
\Lambda_{2}=0.05\end{array}$ \\
\hline 50 & 50 & 929.165 & 453.835 & 754.51 & 819.635 & 1091.04 & 529.719 & 874.974 & 918.588 & 1341.5 & 622.859 & 1067.54 & 1220.17 \\
\hline 50 & 100 & 991.58 & 520.597 & 813.938 & 885.003 & 1143.84 & 591.658 & 925.091 & 973.275 & 1394.09 & 696.385 & 1120.45 & 1281.9 \\
\hline 50 & 150 & 1053.9 & 586.769 & 873.281 & 950.244 & 1196.67 & 653.127 & 975.135 & 1027.86 & 1446.68 & 769.245 & 1173.35 & 1343.53 \\
\hline 100 & 100 & 1053.94 & 587.937 & 872.502 & 951.967 & 1197.0 & 661.827 & 974.584 & 1029.75 & 1446.05 & 775.427 & 1172.66 & 1343.33 \\
\hline 150 & 100 & 1116.16 & 654.306 & 930.981 & 1018.68 & 1250.02 & 729.855 & 1023.99 & 1086.0 & 1498.01 & 852.267 & 1224.87 & 1404.65 \\
\hline
\end{tabular}

Table 3: Variation of critical Rayleigh number for Newtonian, Maxwell, Oldroyd-B and Revlin Erickson liquids with solute Rayleigh number $1 R_{S_{1}}$ and solute Rayleigh number $2 R_{S_{2}}$ for fixed values of $\tau_{1}=0.4, \tau_{2}=0.5, \mathrm{Q}=100, \operatorname{Pr}=5$ and $\mathrm{Pm}=10$

\begin{tabular}{|c|c|c|c|c|c|c|c|c|c|c|c|c|c|}
\hline \multirow[b]{2}{*}{$R_{S_{1}}$} & \multirow[b]{2}{*}{$R_{S_{2}}$} & \multicolumn{4}{|c|}{$\begin{array}{l}\text { Free Free Velocity, Isothermal, } \\
\text { Isoconcentration }\end{array}$} & \multicolumn{4}{|c|}{$\begin{array}{c}\text { Rigid Free Velocity, Isothermal, } \\
\text { Isoconcentration }\end{array}$} & \multicolumn{4}{|c|}{$\begin{array}{l}\text { Rigid Rigid Velocity, Isothermal, } \\
\text { Isoconcentration }\end{array}$} \\
\hline & & $\begin{array}{l}\left(\mathrm{Ra}_{\mathrm{c}}\right)_{\mathrm{N}} \\
\Lambda_{1}=0.4 \\
\Lambda_{2}=0.4\end{array}$ & $\begin{array}{l}\left(\mathrm{Ra}_{\mathrm{c}}\right)_{\mathrm{M}} \\
\Lambda_{1}=0.4 \\
\Lambda_{2}=0\end{array}$ & $\begin{array}{l}\left(\mathrm{Ra}_{\mathrm{c}}\right)_{\mathrm{O}} \\
\Lambda_{1}=0.4 \\
\Lambda_{2}=0.3\end{array}$ & $\begin{array}{l}\left(\mathrm{Ra}_{\mathrm{c}}\right)_{\mathrm{RE}} \\
\Lambda_{1}=0.001 \\
\Lambda_{2}=0.05\end{array}$ & $\begin{array}{l}\left(\mathrm{Ra}_{\mathrm{c}}\right)_{\mathrm{N}} \\
\Lambda_{1}=0.4 \\
\Lambda_{2}=0.4\end{array}$ & $\begin{array}{l}\left(\mathrm{Ra}_{\mathrm{c}}\right)_{\mathrm{M}} \\
\Lambda_{1}=0.4 \\
\Lambda_{2}=0\end{array}$ & $\begin{array}{l}\left(\mathrm{Ra}_{\mathrm{c}}\right)_{\mathrm{O}} \\
\Lambda_{1}=0.4 \\
\Lambda_{2}=0.3\end{array}$ & $\begin{array}{l}\left(\mathrm{Ra}_{\mathrm{c}}\right)_{\mathrm{RE}} \\
\Lambda_{1}=0.001 \\
\Lambda_{2}=0.05\end{array}$ & $\begin{array}{l}\left(\mathrm{Ra}_{\mathrm{c}}\right)_{\mathrm{N}} \\
\Lambda_{1}=0.4 \\
\Lambda_{2}=0.4\end{array}$ & $\begin{array}{l}\left(\mathrm{Ra}_{\mathrm{c}}\right)_{\mathrm{M}} \\
\Lambda_{1}=0.4 \\
\Lambda_{2}=0\end{array}$ & $\begin{array}{l}\left(\mathrm{Ra}_{\mathrm{c}}\right)_{\mathrm{O}} \\
\Lambda_{1}=0.4 \\
\Lambda_{2}=0.3\end{array}$ & $\begin{array}{l}\left(\mathrm{Ra}_{\mathrm{c}}\right)_{\mathrm{RE}} \\
\Lambda_{1}=0.001 \\
\Lambda_{2}=0.05\end{array}$ \\
\hline 50 & 50 & 1205.82 & 686.215 & 1007.39 & 1127.91 & 1300.71 & 746.788 & 1066.62 & 1159.38 & 1532.59 & 846.447 & 1256.71 & 1344.14 \\
\hline 50 & 100 & 1269.71 & 755.931 & 1068.31 & 1195.24 & 1354.3 & 810.971 & 1117.56 & 1215.28 & 1585.46 & 921.5 & 1309.99 & 1405.14 \\
\hline 50 & 150 & 1333.5 & 825.049 & 1129.13 & 1262.45 & 1407.82 & 874.698 & 1168.43 & 1271.07 & 1638.33 & 995.919 & 1363.27 & 1466.05 \\
\hline 100 & 100 & 1333.92 & 827.764 & 1128.46 & 1265.19 & 1408.52 & 886.911 & 1167.98 & 1273.66 & 1638.63 & 1003.83 & 1363.49 & 1466.58 \\
\hline 150 & 100 & 1397.96 & 898.284 & 1188.5 & 1334.81 & 1462.6 & 959.983 & 1218.31 & 1331.79 & 1689.79 & 1083.67 & 1414.98 & 1525.92 \\
\hline
\end{tabular}

Here,

$\left(\mathrm{Ra}_{\mathrm{c}}\right)_{\mathrm{N}}$ - critical Rayleigh number of a Newtoninan liquid $\left(\mathrm{Ra}_{\mathrm{c}}\right)_{\mathrm{M}}$ - critical Rayleigh number of a Maxwell liquid $\left(\mathrm{Ra}_{\mathrm{c}}\right)_{\mathrm{O}}$ - critical Rayleigh number of an Oldroyd B liquid $\left(\mathrm{Ra}_{\mathrm{c}}\right)_{\mathrm{RE}}$ - critical Rayleigh number of a Revlin Erickson liquid

\section{CONCLUSION}

From this study, we can conclude that :

- Stress relaxation parameter, magnetic Prandl number, internal Rayleigh number, and solute Rayleigh numbers are observed to accelerate the onset of convection.

- Strain retardation parameter, Prandtl number,Chandrasekhar number and ratio of diffusivity of solutes and heat diffusivity are observed to decelerate the onset of convection.

- $\left(\mathrm{Ra}_{\mathrm{c}}\right)_{\text {Free-Free }}<\left(\mathrm{Ra}_{\mathrm{c}}\right)_{\text {Rigid-Free }}<\left(\mathrm{Ra}_{\mathrm{c}}\right)_{\text {Rigid-Rigid }}$

- The Newtonian liquid is the most stable followed Revlin Erickson liquid followed by Oldroyd-B liquid and then Maxwell liquid.

\section{ACKNOWLEDGEMENT}

Authors would like to express sincere gratitude to the management of CHRIST (deemed to be University) for the immense support in completing the work.

\section{REFERENCES}

[1] R. W. Griffiths, "The influence of a third diffusing component upon the onset of convection," Journal of Fluid Mechanics, vol. 92, no. 4, pp. 659-670, 1979.

[2] A. Pearlstein, R. Harris and G. Terrones, "The onset of convective instability in a triply diffusive fluid layer", Journal of Fluid Mechanics, vol. 202, no. -1, p. 443-465,1989.

[3] D. Poulikakos, "The effect of a third diffusing component on the onset of convection in a horizontal porous layer", Physics of Fluids, vol. 28, no. 10, p. 3172, 1985.

[4] N. Rudraiah and D. Vortmeyer, "The influence of permeability and of a third diffusing component upon the onset of convection in a porous medium", International Journal of Heat and Mass Transfer, vol. 25, no. 4, pp. 457-464, 1982.

[5] S Rionero, "Triple diffusive convection in porous media", Acta Mechanica, 224(2), pp.447-458,2012.

[6] A. Lopez, L. Romero and A. Pearlstein, "Effect of rigid boundaries on the onset of convective instability in a triply diffusive fluid layer", Physics of Fluids A: Fluid Dynamics, vol. 2, no. 6, pp. 897902, 1990.

[7] I S Shivakumara, K S B Naveen, "Linear and weakly non linear triple diffusive convection in a couple stress fluid layer", 
International Journal of Heat and Mass Transfer, vol.68,pp542$553,2014$.

[8] Sameena Tarannum and S. Pranesh, "Triple diffusive convection in Oldroyd-B liquid", IOSR Journal of Mathematics, vol.12, no.4, pp.07-13,2016.

[9] Sameena Tarannum and S. Pranesh, "Weak nonlinear analysis of triple diffusive convection in Oldroyd-B liquid", Advances and Applications in Fluid Mechanics, vol. 21, no. 4, pp. 389-409, 2018.

[10] Sameena Tarannum and S. Pranesh, "Heat and Mass Transfer of Triple Diffusive Convection in a Rotating Couple Stress Liquid Using Ginzburg-Landau Model", International Journal of Mechanical and Mechatronics Engineering, vol. 11, no. 3,583$588,2017$.

[11] Mahantesh Swamy and W Sidram, "Effect of rotation on the onset of thermal convection in a viscoelastic fluid layer", Fluid Dynamics Research,vol. 45, no.1, p.015504,2012.

[12] K.Sumati and S.Aiswarya,"Linear Stability of Rotating Viscoelastic Fluid Saturated Porous Layer", International Journal of Computational and Applied Mathematics, vol. 12, no. 1, pp. 129-139,2017.

[13] A. Srivastava and A. Singh, "Linear and Weak Nonlinear Double Diffusive Convection in a Viscoelastic Fluid Saturated Anisotropic Porous Medium with Internal Heat Source", Journal of Applied Fluid Mechanics, vol. 11, no. 1, pp. 65-77,2018.

[14] M. Malashetty, M. Swamy and W. Sidram, "Double diffusive convection in a rotating anisotropic porous layer saturated with viscoelastic fluid", International Journal of Thermal Sciences, vol. 50, no. 9, pp. 1757-1769, 2011.

[15] A. Banyal, "A Characterization of the Rivlin-Ericksen Viscoelastic fluid in the Presence of Rotation", International Journal of Physics and Mathematical Sciences, vol. 2, no. 2, pp. 58-64, 2012.

[16] R. Thakur and G. Rana, "Effect of Magnetic Field on Thermal Instability of Oldroydian Viscoelastic Rotating Fluid in Porous Medium", International Journal of Applied Mechanics and Engineering, vol. 18, no. 2, pp. 555-569, 2013.

[17] Pradeep Kumar, H. Mohan and R. Lal, "Effect of magnetic field on thermal instability of a rotating Rivlin-Ericksen viscoelastic fluid", International Journal of Mathematics and Mathematical Sciences, vol. 2006, pp. 1-10, 2006.

[18] Kashif Ali Abro, M. Baig and M. Hussain, "Influences of Magnetic Field in Viscoelastic Fluid", International Journal of Nonlinear Analysis and Applications, vol. 9, no. 1, pp. 99-109, 2019.

[19] P. Siddheshwar and S. Pranesh, "Magnetoconvection in fluids with suspended particles under $1 \mathrm{~g}$ and $\mu \mathrm{g} "$, Aerospace Science and Technology, vol. 6, no. 2, pp. 105-114, 2002.

[20] S. Bhattacharyya and S. Jena, "Thermal instability of a horizontal layer of micropolar fluid with heat source", Proceedings Mathematical Sciences, vol. 93, no. 1, pp. 13-26, 1984.

[21] Y. Tasaka and Y. Takeda, "Effects of heat source distribution on natural convection induced by internal heating", International Journal of Heat and Mass Transfer, vol. 48, no. 6, pp. 1164-1174, 2005.

[22] B. Bhadauria, "Double-Diffusive Convection in a Saturated Anisotropic Porous Layer with Internal Heat Source", Transport in Porous Media, vol. 92, no. 2, pp. 299-320, 2011.

[23] C. Kanchana and Y. Zhao, "Effect of internal heat generation/absorption on Rayleigh-Bénard convection in water well-dispersed with nanoparticles or carbon nanotubes", International Journal of Heat and Mass Transfer, vol. 127, pp. 1031-1047, 2018.

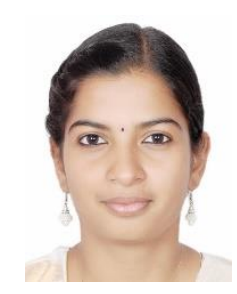

\section{AUTHORS PROFILE}

Gayathri Melathil completed her post graduation degree in Mathematics from CHRIST (deemed to be University), Bengaluru, Karnataka, India. Her research interests include fluid mechanics and computational fluid dynamics. Currently she is a research scholar in CHRIST (deemed to be University).

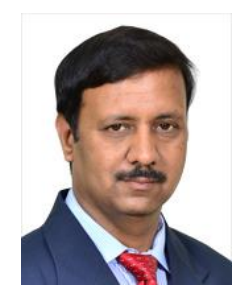

Dr Subbarama Pranesh completed his postgraduate degree from Bangalore University, Bengaluru, Karnataka, India. He obtained his Ph.D in Mathematics in 2001 from the same university. His research interests include fluid mechanics, suspensions and computational fluid dynamics. $\mathrm{He}$ is currently working as Professor in the Department of Mathematics, CHRIST (deemed to be University), Bengaluru, Karnataka, India.

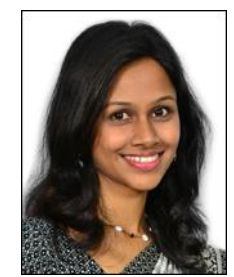

Dr Sameena Tarannum received MSc and MPhil in Mathematics from CHRIST (deemed to be University), Bengaluru, Karnataka, India. She was awarded Ph.D in Mathematics in the year 2018 from the same University. Her research interests are computational fluid dynamics, applied and computational mathematics, mathematica modelling and non linear analysis. She is currently working as Assistant Professor in the Department of Professional Studies, CHRIST (deemed to be University). 